\title{
The Experiences of Medical Graduates to Peer Teaching in a Large Group
}

\author{
Shilpi G. Dixit ${ }^{1}$ Brijendra Singh ${ }^{2}$ Pushpa Potaliya ${ }^{1}$ \\ ${ }^{1}$ Department of Anatomy, All India Institute of Medical Sciences, \\ Jodhpur, Rajasthan, India \\ 2Department of Anatomy, All India Institute of Medical Sciences, \\ Rishikesh, Uttarakhand, India
}

\author{
Surajit Ghatak ${ }^{1}$
}

Ann Natl Acad Med Sci (India) 2019;55:28-33

\begin{abstract}
Address for correspondence Shilpi G. Dixit, Department of Anatomy, All India Institute of Medical Sciences, Jodhpur 342005, Rajasthan, India (e-mail: shilpidr@gmail.com).
\end{abstract}

\begin{abstract}
Medical education is persisting to be chiefly structured around faculty authority and didactic lectures. This upholds idiosyncratic spirited milieu rather than the two-way ones desirable for the relevance in current clinical practice. The present study was set to refurbish the at hand scenario by the assimilation of active learning strategy as seminars in human anatomy curriculum of medical undergraduate program. The underlying purpose of this study was to evaluate the inclusion of varied modalities of active learning stratagem. The aim was also to construct an interactive two-way classroom prospects for thorough understanding, conceptualizing, problem solving, and utilizing student oriented presentations to elucidate multifarious subject concepts in an easy and de novo approach. The study was conducted on First Professional MBBS students in the Department of Anatomy at the Institute by a seminar activity for active comprehension followed by student feedback. A qualitative and quantitative analysis was done where close-ended questions were concerned with the usefulness of the

Keywords

- anatomy

- seminar activity

- active learning

- feedback activity and significant aspects related to the understanding of anatomy. The scores for student feedback were graded in a five-point Likert's scale. The institutional experience of facilitators of this tertiary care institution and their efforts in successful implementation of seminar activity have set an example and responsibility for the medical educators all over the globe to use more and more of such instructional approaches.
\end{abstract}

\section{Introduction}

The key aspect in student-centered learning is well illustrated by various workers by apprentice activities. The major emphasis is always on the experiences attained during and preceding the schedule. The progression is the major concern instead of the final learning outcome. The literature is also suggestive of handing over the mode of learning to be chosen by learners themselves or in conciliation with the educator. ${ }^{1}$ The studies many a time accentuated on the significance of the use of various means of assessment employed and the reason behind it. It is also important to note that medical students are expected to learn, comprehend, and execute the learned skills in a limited training. ${ }^{2}$ It was reported that the ways of assessment shall be altered by moderators for a better learning experience. Such ideology is still relevant after so many years. ${ }^{3}$ Still there are scores of instances showing employment of poor assessment stratagem in medical education curriculum.

In today's constantly evolving era, education is also showing marked alterations. The contemporary cohort of learners wishes delightful atmosphere, self-command, apparent prospects and expositions, personal empathy with the mentors, integrity, and unconstrained utilization of technology.4.6

The innovative trend incorporates teaching with extensive utilization of active learning practices so as to augment the performance. ${ }^{7} \mathrm{~A}$ well-known fact is that learning and participation are in each other's pocket. ${ }^{8}$ Such studies by eminent workers worldwide optimized the facilitators and persuade them to accustom and modify their instructional archetype in accordance to the cohort of neologist learners. ${ }^{6}$ 
In medical education, many facilitators are harmonizing specifically amid the core aim for assessment as comprehension control and assessment as integral component of the learning progression. Nowadays, the major emphasis is on creating learning environment that stresses on student-centered ideas and promotes soaring activity amongst students. With this, we were intended to plan a mode of assessment that would come out as an unambiguous tool for learning, and also provide the facilitators with an unswerving basis for righteousness while allocating marks. In the present study, we shall be elucidating and describing our institutional experience along with drawing some conclusions and determining whether this innovation regarding the use of seminars would be well received and effective for student's teaching-learning of anatomy.

The rationale of this study was to appraise the inclusion of varied modalities of active learning stratagem. It included encouraging camaraderie, enhancing interpersonal and communication skills, and commencing and formulating a system for disseminating intricate medical concepts in an accessible uncomplicated approach for learners to employ in the future clinical scenario in the anatomy course of the undergraduate medical curriculum.

\section{Materials and Methods}

A study was conducted on First Professional MBBS students in the department of Anatomy at the All India Institute of Medical Sciences, Jodhpur, by a seminar activity for the active comprehension followed by the student feedback. The anatomy curriculum for undergraduates comprises both smallgroup (up to 12 students) cadaveric dissection sessions and large-group lecture classes of 1 to 2 hours each.

In an endeavor to sever the monotony and persuade the apprentices with dynamic learning, an activity of student seminar was conducted. The activity comprised two elements, a 10 minutes presentation by student, followed by 5 minutes for the postpresentation discussions.

In the introductory assembly, students were made well-versed with the active learning strategies which were included as an activity instead of proverbial lectures. As an enticement other than the benefits of individual learning and the skill development that would place them in better stead with future colleagues and patients, students were also briefed that involvement in the exercise would harvest part of their final evaluation.

\section{Student Presentations}

Faculty members prepared a list of topics appropriate for the presentation out of whole anatomy curriculum. Each student was allotted a topic according to their roll numbers and this list was displayed 2 weeks before starting the activity. In these 2 weeks, students prepared their topics and guidance was given by the allotted supervising faculty member. The activity was performed in the hours scheduled for anatomy lectures and practicals only. Thus there was no rescheduling of timetable of other subjects in the First Professional course. The students for the presentation were randomly selected by the sweepstake system. On each day of activity, a random student was asked to pick up blinded roll numbers from the given box. These picked-up students were to present their topics on that particular day. The sessions were moderated by at least three faculty members always at any point of time along with all the in-house residents during whole activity. Students were called to the podium and asked to summarize the topic allotted in stipulated slot. The student presenters were instructed to use various props and modes of choice as models, bones, charts, or blackboard to elaborate and elucidate the topic. They were discouraged to use the electronic modes and preprepared printed matter. The reason to do so was to encourage them to be creative and learn the diagrams as well.

\section{Postpresentation Discussions}

Subsequent to the presentation, the session was made open for the audience to carry out the discussion. Stipulated time was assigned for this section also. Audience students were encouraged to ask questions regarding the concerned topics and were permitted to highlight the faults in the presentation in a constructive mannerism. Moreover, at the same time the ideas were invited to rectify them. The students were expected to stress upon the missed points, in case, by the presenter. The participant students were allotted marks by all the moderating faculties. In addition, the provision of scoring marks was there for the audience students too depending on the queries and the valid points rose. The final comment and suggestion was by the faculty regarding the topic, way of presentation, flaws, and strengths etc. At the end, applause was done to motivate and encourage the presenters for their efforts.

The marks allotted to each student by various faculties including its presentation and active participation in others sessions was tabulated and a final score was obtained.

At the end of a fortnight long activity of the seminar, a pretested questionnaire was disseminated among the students about the worth of this educational activity. It comprised both closed- and open-ended questions. Close-ended questions were concerned with the usefulness of the activity and significant aspects related to the understanding of anatomy and were graded in a five-point Likert's scale.

The quantitative data were entered and analyzed through SPSS for Windows version 16. The qualitative data were assessed through thematic analysis.

\section{Observation and Results}

Subsequent to the seminar activity, the students were given a questionnaire to be filled. All the 90 participants voluntarily participated with consent. They were given necessary instructions and requested to fill the questionnaire. It was completed and returned with full keenness.

The mean age of our sample was $18.5( \pm 1.5)$ years and it consisted of $69(76.66 \%)$ male and $21(23.33 \%)$ female students.

The outcome of students' retort to the feedback form is represented in - Fig. 1. Analysis of statistical feedback data from the seminar-activity questionnaire was done using the Excel program. It was presented graphically as well as accounted in descriptive manner. 


\begin{tabular}{|c|c|c|}
\hline S. No. & & $\begin{array}{l}\text { Strongly Agree Neutral Disagree Strongly } \\
\text { agree }\end{array}$ \\
\hline 1. & $\begin{array}{l}\text { Were Seminars Informative } \\
\text { a. For speakers } \\
\text { b. For audience }\end{array}$ & 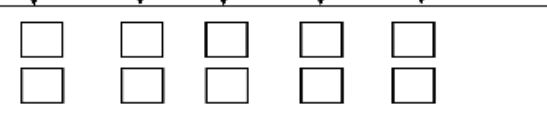 \\
\hline 2. & Retaining information was better through seminars & $\square \quad \square \quad \square \quad \square \quad \square$ \\
\hline 3. & Preparation required more than a week's time & $\square \quad \square \quad \square \quad \square \quad \square$ \\
\hline 4. & Peers were of help in the preparation & $\square \square \square \square \square$ \\
\hline 5. & $\begin{array}{l}\text { Declaration of schedule and topies well ahead helped in preparing } \\
\text { better }\end{array}$ & $\square \quad \square \quad \square \quad \square \quad \square$ \\
\hline 6. & $\begin{array}{l}\text { One should read the topics presented by others after the seminar } \\
\text { also }\end{array}$ & $\square \quad \square \quad \square \quad \square \quad \square$ \\
\hline 7. & It is a good way of revision & $\square \quad \square \quad \square \quad \square \quad \square$ \\
\hline 8. & It is a good source of knowledge of topics & $\square \square \square \square \square$ \\
\hline 9. & Sessions were open to ideas and interactions & $\square \square \square \square \square$ \\
\hline 10. & $\begin{array}{l}\text { Improved hesitation of public speaking and highlighted the } \\
\text { shortcomings }\end{array}$ & $\square \quad \square \quad \square \quad \square \quad \square$ \\
\hline 11. & Question and answer session were of importance & $\square \square \square \square \square$ \\
\hline 12. & Drawing of diagrams were improved by it & $\square \quad \square \quad \square \quad \square \quad \square$ \\
\hline 13. & $\begin{array}{l}\text { Seminars are of importance regarding } \\
\text { a. Long-questions } \\
\text { b. Short-questions } \\
\text { c. Viva-voce }\end{array}$ & 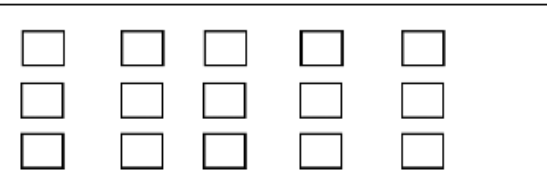 \\
\hline 14. & $\begin{array}{l}\text { Motivational aspect } \\
\text { a. Increased the interest in topics and subject } \\
\text { b. Motivation to learn }\end{array}$ & $\begin{array}{l}\square \quad \square \\
\square \quad \square\end{array}$ \\
\hline 15. & $\begin{array}{l}\text { Improved facilitation of learning by different methodology than } \\
\text { didactic lectures }\end{array}$ & $\square \square \square \square \square$ \\
\hline 16. & $\begin{array}{l}\text { Helped in relating text book knowledge to clinical aspect in open } \\
\text { discussions }\end{array}$ & $\square \quad \square \quad \square \quad \square$ \\
\hline 17. & In-depth interactions cleared doubts & $\square \square \square \square$ \\
\hline 18. & $\begin{array}{l}\text { Direct prompt feedback from faculty has improved } \\
\text { a. Speaker } \\
\text { b. Audience } \\
\text { c. Both }\end{array}$ & $\begin{array}{lllll}\square & \square & \square & \square & \square \\
\square & \square & \square & \square & \square \\
\square & \square & \square & \square & \square\end{array}$ \\
\hline 19. & Role of strictness of attendance & $\square \square \square \square \square$ \\
\hline 20. & Overall rating of seminars & $\square \quad \square \quad \square \quad \square \quad \square$ \\
\hline
\end{tabular}

Fig. 1 Feedback questionnaire given to the students.

The majority of students agreed that this seminar was informative and useful and encouraged creativity and teamwork. Moreover, most of them agreed that skills related to presentation, counseling, and evidence-based medicine were also enhanced.

A good number (40\%) of students agreed that the seminars were informative and a learning experience for speakers, whereas around $58.8 \%$ of them considered it to be just an average medium of the audience. In contrast, $82.22 \%$ found the retaining of information difficult through the activity (-Fig. 2).

Very less of the fraction considered it to take more than a week time for preparation and around 30\% found the peer group a great help in preparing the topic for presentation. 


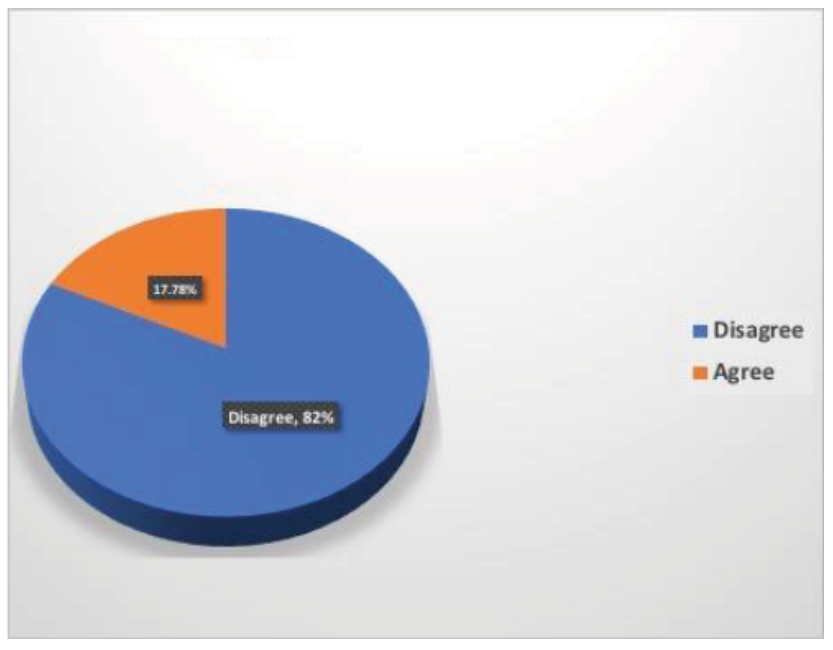

Fig. 2 Chart showing retaining information was better through seminars.

They also favored the declaration of schedule and topics well ahead which helped them in preparing the topics better. Not many of the students $(31.1 \%)$ were interested in reading the topics presented by others even after the seminars. Acceptability of this novel method as a model for revision and as a source of knowledge was found less among the students. For a larger group (46.66\%), the post seminar session were open to ideas and interactions. Question and answer session were of importance and drawing of diagrams (31.11\%) was also reportedly found to be improved. Out of whole census, $65.55 \%$ reported to have improved the hesitation of public speaking and also found that their shortcomings were highlighted in a productive mannerism ( - Fig. $\mathbf{3}$ ).

The students found the seminars to be of help in practical examination in answering the questions at time of viva voce $(29 \%)$. Moderate percentage agreed for it to be helpful of importance regarding long and short questions. Regarding the motivational aspect, again most students found it just to be a not good to fair medium to enhance the interest in topics and their motivation to learn. Around more than half participants $(60 \%)$ were in support of collateral methodology other than didactic lectures in curriculum (-Fig. 4).

Such presentations by the peer group also found to help them in relating text book knowledge to clinical aspect in open discussions (34.44\%). A mixed response was found regarding the impact of direct prompt feedback from faculty in the improvement (-Fig. 5).

Interesting was to observe that ample number of students were in disagreement $(25.55 \%)$ with the mandatory attendance during whole activity by the facilitators. Still students also found it to be very good (18.88\%) and excellent (24.44\%) way to expose as maximum as possible participants in activity. Overall, by and large, big assemblage (41.11\%) of students found this activity useful for their learning.

Students were also asked open-ended questions regarding the role of seminar activity. One question was "What did you like BEST about this seminar?" In informal discussion, students responded to this question. The affirmative theme that was highlighted included an augmented intensity of interest

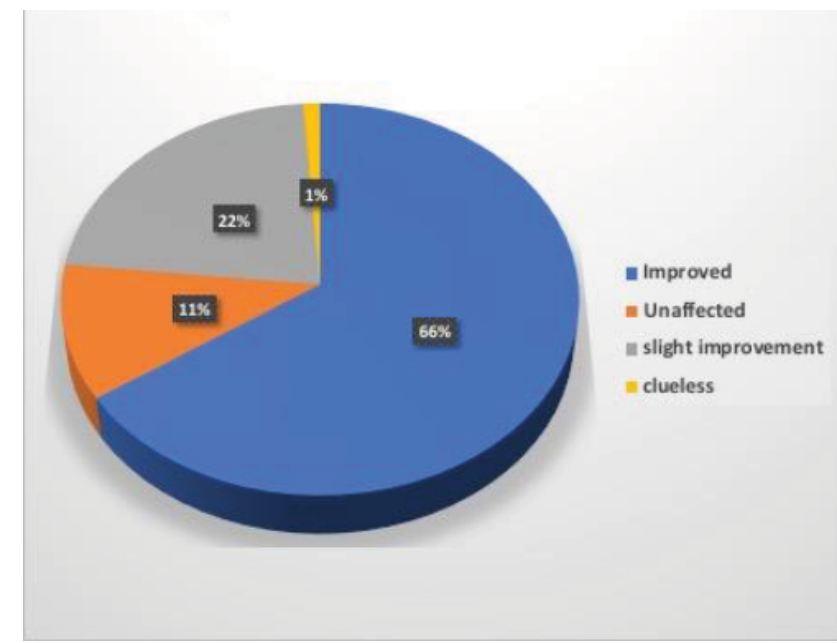

Fig. 3 Chart showing opinion regarding effect on public speaking.

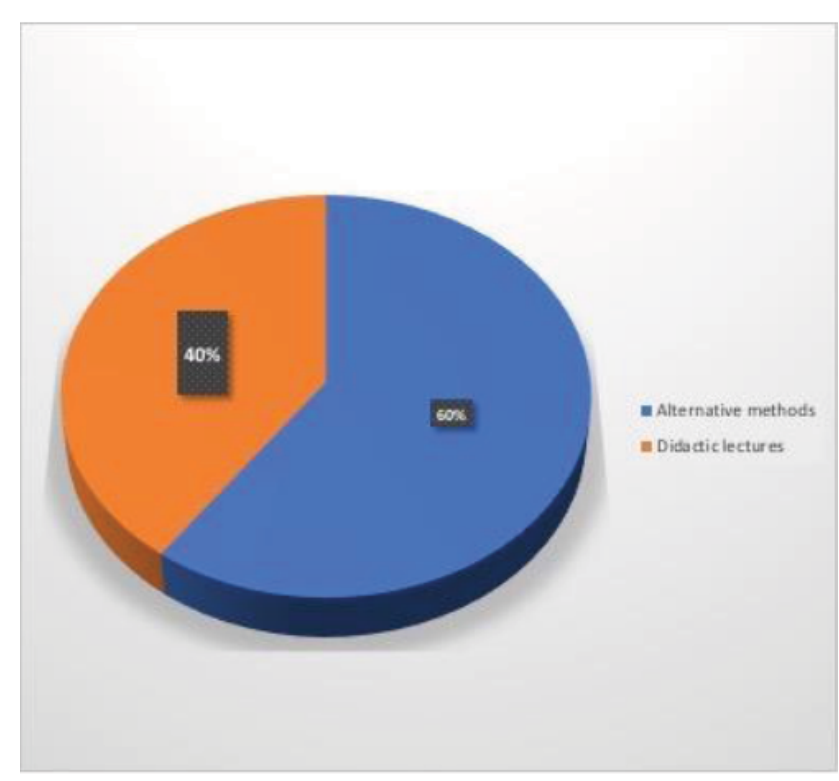

Fig. 4 Chart showing improved facilitation of learning by different methodology than didactic lectures.

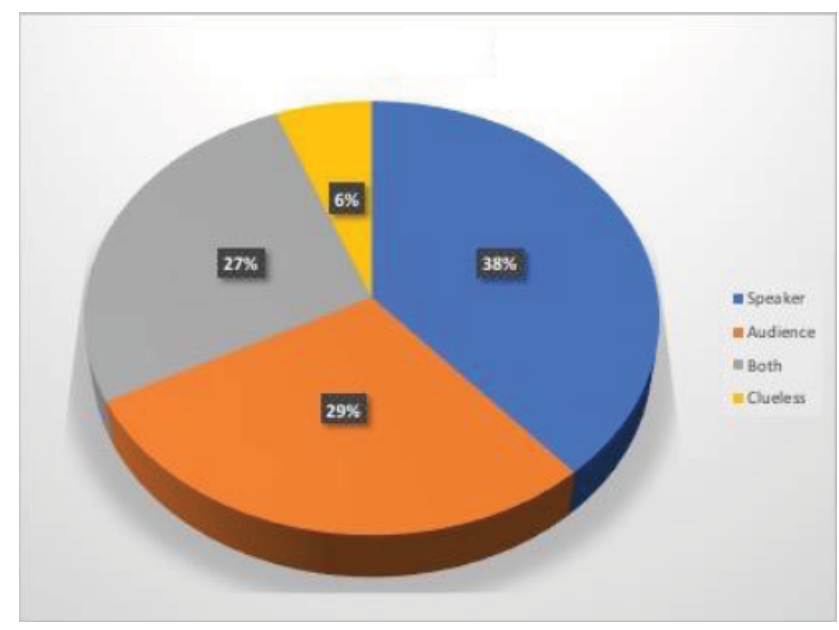

Fig. 5 Chart showing direct prompt feedback from faculty has improved. 
in their studies and the break from the boredom and repetitiveness of lectures in a monotonous manner throughout the curriculum. It was also emphasized that such commotion was distinctive by being concurrently ingenious, tranquil and on the whole educational for the students.

Regarding the question of LEAST liked about the seminars, students were bit hesitant initially to answer. But still after gaining the confidence of them by explaining them the utility of this particular opinion in the whole activity, the few responded to this question. The unswerving theme stressed in this was the appraisal or prompt feedback offered by the faculty at the closing stages of each presentation. Students found that the faculty was contemptuous of their efforts and in few cases, open criticism was not taken in a constructive manner. The students already in low esteem and public speaking skills found it not to be of any help as it sometimes happening to lower their confidence even more. The major fact behind this was that few students took the critique in a personalized way.

It was also the opinion that the faculty apparently took this entire activity as a serious scholastic activity; while for few students, acceptability for a novel approach was nonpalatable. This disparity of insight may have rooted a divergence and in turn was the reason behind major off-putting citations.

\section{Discussion}

A futuristic envision for an advanced panel approach to the patient management in clinical set-up has motivated the educators for active participation of medical students in their personal learning and training. This encourages and endows with prospects for the thinking skills development and interpersonal skills desired to function efficiently in the new setting. Such exercises with student involvement accentuate assemblage activities for the medical students. Active learning utilizes approaches that deal with a greater range of individual learning modes and encourages the efficient team work and interpersonal skills during the progression.

It is most important for the curriculum planners to understand the objectives of the course and the basic requisite of the learners. This comprehension will help them in choosing diverse approaches that can be exercised to involve students in the self-learning. Out of wide variety of active learning, which includes model making, demonstrations, extempore, use of simulators, acts, painting exercises, problem solving, case studies, and learning through games etc., the student led seminars is also an imperative strategy. Worldwide literature has revealed that these approaches are extensively used nowadays as novel method of teaching-learning in medical education.

During the practical hands-on in dissection hall, it is simple to engross students in dialogue and active learning. Whereas, the greater part of theory is covered under didactic lectures. It is apparent that the tedium and bleakness with continuous one-way communication makes the students uninterested in this lecture format of teaching-learning. ${ }^{9.10}$ In the analysis of student feedback, the integration of active learning approaches was appreciated by the students. ${ }^{11}$ Still in contrast, the major issue raised was the time of activity in curriculum as it was selected at the end before exams. They found it good for revision but it was a high time for their self-study too. ${ }^{12}$ The literature mining made a valid point of various benefits of dynamic, student-centered learning in comparison to conventional didactic lecture. It is noteworthy that no single method is complete and merits of didactic lecture can also not be denied. ${ }^{13,14}$ In other words, there lies a difference in envisaging crisis and really doing something to solve it, the approach of active learning offers an occasion for the learners to do something to decipher the problem. ${ }^{5}$

Few students also had opinion of such activities to be a misuse of their high time before examination. They also have a view that for few topics, stipulated time was either insufficient or their way of elucidation needed more time to cover-up complete topic. This is not unusual. It is evident and well-known finding that learners are unwilling in incorporating such active learning modes as their preset mind is unable to consider such tangential ways positively in the scholastic setting. ${ }^{4,5,15,16}$ The passive existences during didactic lectures is rather an easy way for nonserious students and even for majority as students in India are habituated of learning through such ways only.

Transforming the conventional form of seminar by addition of questionnaires, test sessions, role plays, and group discussions with seminars have found to enhance the students' attentiveness, zeal, and motivation; hence, accentuating the learning spirit. ${ }^{17}$

The notion of peer involved experimental learning is further reinforced by socio-cultural learning model, which elucidates how involvement and interaction with peers aids students in acquiring knowledge and comprehension. ${ }^{18}$

The present study and its successful implementation have set an example and responsibility for the medical educators all over the globe to the more and more use of such instructional approaches. The notion of considering the lateral activities as not the serious academic teaching-learning should be changed. From prehistoric times, medical education is renowned for its blending of classical and novel strategies which keep the educators as well as learners as well at ease. Also for the mass of students who are apprehensive of their performance in routine exam format, get a fair chance for improving the grades and scores.

\section{Conclusion}

Inclusion of active learning process enhances not only students understanding of subject but also their set of skills that benefits them in their clinical practice in future career. Although the outcome of study is preliminary, by and large limited by the results of a single exercise for one academic session, the student-led seminar activity may have the potential to improve training for medical undergraduates; the challenge presented here can be justified further with auxiliary exploration.

Conflict of Interest

None declared. 


\section{References}

1 Boud D, Assessment and learning: contradictory or complementary. In: Knight P, ed. Assessment and Learning in Higher Education. London: Taylor \& Francis; 1995: 35-48

2 Hernández-Torrano D, Ali S, Chan CK. First year medical students' learning style preferences and their correlation with performance in different subjects within the medical course. BMC Med Educ 2017;17(1):131

3 Fowler G. Postmodernism: this changes everything! J Stud Cent Learn 2003;1(2):87-95

4 Gomathi KG, Shaafie IA, Venkatramana M. Student-led seminars as a teaching-learning method-effectiveness of a modified format. South East Asian J Med Educ 2014;8:82-84

5 Parekh M, Munjappa H, Shinde S, Vaidya S. Student perceptions on activity-based learning in physiology. Natl J Physiol Pharm Pharmacol 2018;8:590-593

6 Nelson C. Student diversity requires different approaches to college teaching, even in math and science. Am Behav Sci 1996;40(2):165-175

7 Wlodkowski RJ. Fostering motivation in professional development programs. New Dir Adult Contin Educ 2003;98:39-47

8 Rao M. The rapid-response: a break during lecture. Adv Physiol Educ 2006;30(2):95

9 Prober CG, Heath C. Lecture halls without lectures-a proposal for medical education. N Engl J Med 2012;366(18):1657-1659

10 Terenzini E, Pascarella P. Living with myths: undergraduate education in America, change. Magazine of Higher Learning 1994;26(1):28-32
11 Wolff M, Wagner MJ, Poznanski S, Schiller J, Santen S. Not another boring lecture: engaging learners with active learning techniques. J Emerg Med 2015;48(1):85-93

12 Jaarsma AD, Dolmans DD, Muijtjens AM, Boerboom TT, van Beukelen P, Scherpbier AJ. Students' and teachers' perceived and actual verbal interactions in seminar groups. Med Educ 2009;43(4):368-376

13 Russell IJ, Hendricson WD, Herbert RJ. Effects of lecture information density on medical student achievement. J. Med Educ 1984;59(11 Pt 1):881-889

14 Padgett RD, Johnson MP, Pascarella ET. First-generation undergraduate students and the impacts of the first year of college: some additional evidence. J Coll Student Dev 2012;53(2):243-266

15 Panitz T. Why more teachers do not use student centered learning techniques and policies needed to encourage positive changes. J Stud Cent Learn 2003;1(2):55-60

16 Spruijt A, Jaarsma ADC, Wolfhagen HAP, van Beukelen P, Scherpbier AJ. Students' perceptions of aspects affecting seminar learning. Med Teach 2012;34(2):e129-e135

17 Palappallil DS, Sushama J, Ramnath SN. Effectiveness of modified seminars as a teaching-learning method in pharmacology. Int J Appl Basic Med Res 2016;6(3):195-200

18 de Menezes S, Premnath D. Near-peer education: a novel teaching program. Int J Med Educ 2016;7:160-167 